\title{
PERANAN PSIKOLOGI OLAHRAGA DALAM MENGEMBANGKAN OLAHRAGA PRESTASI DI INDONESIA
}

\author{
Dimyati \\ Universitas Negeni Yogyakarta
}

\begin{abstract}
This anticle ty to serve various study about the important of Sport Psychology to increase the Indonesian sport performance. Sport Psychology is needed to support the applicalion of sport science to increase sport performnce. Various study indicated that the Sport Psychology has a real contribution and role in increasing sport performance. But in Indonesia Sport Psychology $s$ less getting place and attention among sport practitioners and people in higher education who has responsibility b manage and develop Psychology Scienc.e

Some efforts to develop the Sport Psychology are needed to increase its contribution in increasing sport performence. Among those are: (1) growing the awareness to all component who concerned with sport performance about the important of sport psychology; and (2) Improving human resource in the fiald of Sport
\end{abstract}

Keywords: sportpsychology, development, sport perf ormance

\section{Pengantar}

Undang-undang Republik Indonesla Nomor: 3 tahun 2005 tentang SIstem Keolahragaan Nasiona! yang lebih dikenal dengan undang-undang olahraga secara eksplisit menegaskan bahwa olahraga prestasi adalah olahraga yang membina dan mengembangkan olahragawan secara terencana, berjenjang. dan berkelanjutan melałul kompetisl untuk mencapai prestasi dengan dukungan ilmu pengetahuan dan teknologl keolahragaan. Tersirat dalam batasan ltu bahwa olahraga prestasi merupakan suatu sistem yang terdiri dari berbagal komponen. Salah satu komponen untuk mewujudkan prestasi adalah dukungan IImu keolahragaan. Hagg (1994) menegaskan ilmu keolahragaan itu sendirl tersusun darl tujuh bldang teorl dasar, yaitu kesehatan olahraga, blomekanika olahraga, pslkologi olahraga, pedagogl olahraga, sosiologi olahraga, sejarah olahraga, dan fllsafat olahraga. Pslkologi Olahraga merupakan satu dari tujuh bidang teori yang menjadl batang tubuh pengetahuan (body of knowledge) ilmu keolahragaan.

Lutan (1997), mengatakan bahwa dl lingkungan Komlte Olymplade Amerika pembinaan olahraga prestas| telah menerapkan seperangkat ilmu, salah satunya adalah Psikologi Olahraga. Psikologi Olahraga menurut Anshel (1990) adalah IImu yang mengkaji perilaku manusla dalam konteks olahraga prestasi yang dipengaruhi oleh tiga unsur utama yang saling terkait satu sama lainnya, yaltu atlet thu sendiri, pelatih dan lingkungan.

Usaha pembinaan olahraga prestas! yang tinggi, merupakan masalah yang rumit dan kompleks dan banyak tergantung serta dlpengaruhi oleh berbagai faktor (Nossek, 1982). Pembinaan olahraga tidak cukup hanya mengandalkan dana, pengorganisasian dan manajemen serta kerja keras, tetapi yang tidak kalah pentingnya adalah peran darl pendekatan ilmlah berbagal disiplin ilmu. IImu-IImu yang langsung dapat dimanfaatkan untuk memacu penlngkatan prestasi olahragawan yaitu IImu-ilmu Medik, llmu Kepelatihan dan Psikologi (Selyobroto, 1993). 
Lebih khusus, Pate dkk. (1993) menegaskan bahwa sampai saat ini ada tiga ilmu dasar yang telah berkembang menjadi subdisiplin ilmu yang mendukung praktek kepelathan olahragawan yang sempuma, yaitu bidang Pslkologi Olahraga, Biomekanika dan Psikologi Latihan. Harsono (Singgih, dkk, 1996) menegaskan bahwa dari berbagai ilmu tersebut, Psikologi Olahraga khususnya yang menyangkut proses-proses mental-emosional atlet menjadi kontributor yang semakin menentukan dalam pembinaan serta peningkatan prestasi atlet. Lebih lanjut dijelaskan oleh Singih (1989; 2001) bahwa pelath dan pembina olahraga di Indonesia lebih dominan memberikan latihan fisik dan teknik, tetapi melupakan latihan mental yang sesungguhnya merupakan faktor yang sangat penting (Kompas, 8 Mei 2004).

Tulisan ini akan mencoba mengkaji bagaimana peran Pskologi Olahraga dalam menunjang olahraga prestasi. Pada bagian pertama, akan dibahas Psikologi Olahraga di antara perkembangan Psikologl sebagai pusat kajlan ilmu. Pada bagian kedua, akan dibahas tujuan dan ruang lingkup Psikologi Olahraga, dan beberapa persoalan yang dlhadapi. Tulisan ini akan diakhiri dengan pembahasan mengenal upaya pengembangan Pskologi Olahraga da|am pembinaan olahraga prestasi Indonesia di masa yang akan datang.

\section{Kaltan Psikoiogi dan Psikologi Olahraga}

Nasib Psikologi Olahraga masih belum menggembirakan. Para pengambil kebljakan di perguruan tinggi masih belum memandang Psikologi Olahraga menjadi sesuatu yang penting untuk dikajl dan dikembangkan. Salah satu PT yang serius mengkaji ilmu Psikologl Olahraga adalah Unlversitas Indonesia (UI) yang membuka program stud Psikologl Olahraga, namun itu pun baru dibuka 4-5 tahun belakangan ni. Kondisi ini secara tidak langsung berimplikasi terhadap perkembangan olahraga prestasi di Indonesla, karena kajian IImu-ilmu keolahragaan khususnya Psikologi Olahraga belum dikelola dan dikembangkan sebagai bagian yang penting di Perguruan Tinggi $d$ Indonesia. Padahal ilmu itu merupakan bagian yang penting untuk menunjang dalam pembinaan olahraga prestasi.

Terdapat kaitan yang kuat antara kajian-kajian dalam berbagai bidang Psikologi dengan Psikologi Olahraga. Weinberg \& Gould (2003); William. dan Starub (1980) menegaskan bahwa dilihat dari luas bidangnya, kaitan bidang-bidang Psikologi lainnya dengan Psikologi Olahraga sangat besar. Psikologi Olahraga dapat memanfaatkan dasar-dasar Psikometri untuk melakukan berbagal evaluasi psikologis, balk dalam tahap pembinaan dalam upaya mencetak atlet agar menjadi atlet yang handal, melakukan seleksi maupun penempatan pada salu cabang olahraga atau suatu tugas tertentu. Dasardasar penelitian dalam bldang Psikologi juga dapat diterapkan dalam bidang Psikologi Olahraga, misalnya untuk meneliti berbagal faktor yang menunjang atau menghambat prestasl atlet. Psikologi Olahraga berhubungan erat dengan Psikologl Perkembangan untuk memahami tahaptahap perkembangan, peranan faktor bakat, latar belakang keturunan, cri kepribadian dasarnya (traittheory),juga masa-masa kritis (critical period) untuk mendapatkan rangsangan dalam bentuk program latihan serta memahami tahap perkembangan seorang atlet ketika berada pada usia emas (golden age) untuk mencapal puncak prestasi (poak performance). Setiap atlet adalah unk dan berbeda baik dilihat dan karakteristik fisiknya, perilaku sosialnya dan kapasitas intelektualnya (Bompa, 2000).

Dasar-dasar Psikologi Belajar (Psychology of Leaming) dapat diterapkan juga dalam Psikologi Olahraga, khususnya dalam latihan sehani-hari. Hukum efek dari Throndike (the law of effect) dapat dimanfaatkan untuk menciptakan suasana atau permainan serta lathan agar lebih menyenangkan sehlngga ada keinginan untuk melakukan lagi. Keadaan ini dlperkuat dengan pujian dan hukuman (neward dan punishment) sebagai upaya untuk membentuk kebiasaan dan kepribadian. Prinsip-prinsip latihan yang didasarkan pada 
Psikologi Belajar dengan prinsip pengulangan (repetition, drilling, sequence), ulangan penguatan (reinforcement), umpan balik (foedback) dan penentuan sasaran (goal-setting).

Prinsip dalam Psikologi Sosial seperti kerja sama dan bersatu padu (kohesivitas tim) dalam mencapai satu tujuan sangat berguna untuk memahami dinamika kelompok, di samping hubungan-hubungan antar pribadi, baik antar atlet, atlet dengan pelatih, dan atlet dengan pembina bahkan hubungan atlet dengan masyarakat.

Semua kajian sebagaimana dijelaskan d atas dapat dikelola dan dikembangkan dalam berbagai dimensi ilmu psikologi. Singgih (2004), menegaskan bahwa pengajaran pada Psikologi Olahraga tidak dapat terlepas dari sejumlah cabang psikologi seperti Psikopatologi, Psikologi Klinis, Psikologi Konseling dan Psikoterapi, Psikologi Perkembangan, Psikologi Eksperimen, Psikologi Kepribadian, Pslkologi Sosial, Psikologi Belajar, dan Psklkologi Faal. Berbagai bidang Psikologi tersebut dikaji dan dikembangkan di Perguruan Tinggi yang mengelola ilmu Psikologi. Oleh karena itu apabila kajiankajian itu dapat dlaplikasikan daiam bldang Psikologi Olahraga, maka Psikologi Olahraga akan berkembang dan dapat memberi kontribusi nyata dalam pembinaan olahraga prestas| di Indonesia. Artinya bila bangsa ini ingin mengembangkan olahraga prestasi, maka yang menjadi perhatian tidak semata-mata aspek fisik, alat dan fasilitas olahraga, dan dana yang dikembangkan. Aspek-aspek kajian ilmu keolahragaan umumnya dan Psikologi Olahraga khususnya yang diaplikasikan dalam pembinaan olahraga prestasi amat besar kontribusinya.

\section{Tujuan dan Ruang Lingkup Psikologi Oiahraga}

Weinberg \& Gould (2003) menegaskan bahwa ada dua tujuan utama mengkaji Psikologi Olahraga, yaitu (1) mengkaji pengaruh dari faktor-faktor psikologis terhadap penampilan atlet; dan (2) mengkaji pengaruh dari keikutsertaannnya dalam aktivitas jasmani dalam mengembangkan kesehatan dan kesejahteraan. Dalam tataran yang lebih luas, Anshel (1990) memberikan batasan bahwa Psikologi Olahraga adalah ilmu yang mempelajari perilaku manusia dalam konteks olahraga prestasi. Berbicara tentang olahraga prestasi olehnya dikatakan lebih lanjut bahwa tidak bisa lepas dari tiga faktor utama, yaitu atlet, pelatih, dan lingkungan yang saling terkait antara satu sama lainnya. Lebih lanjut digambarkan oleh Anshel sebagai berikut:

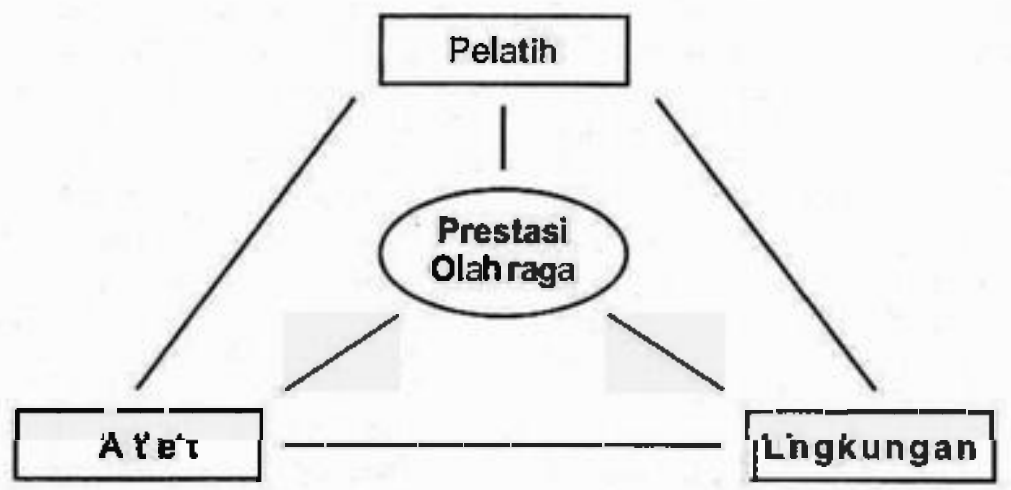

Gambar 1. Faktor-faktor yang Berpengaruh dalam Olahraga Prestasi 
Berdasarkan gambar tersebut diketahui bahwa kajian tentang olahraga prestasi tidak bisa dilepaskan dari tiga unsur utama yang saling bertiubungan satu sama lain. Unsur-unsur tersebut, yaitu pelatih, lingkungan, dan atlet ku sendiri. Hubungan yang saling mempengaruhi prestasi olahraga, misalnya faktor lingkungan sepertl induk organisasi (contoh PSSI) yang memberikan kejelasan akan hak dan kewajiban kepada pemain dan pelath seperti jaminan hidup, perumahan dan sebagainya akan membuat mereka lebih berkonsentras! untuk berlatih dan bermain. Begitu pula gaya dan kualitas kepemimpinan seorang pelatih akan berpengaruh terhadap atlet dalam proses pembinaannya. Di lain pihak, kondisi atlet ku sendiri seperti motivasi, sikap, kepribadian akan menentukan prestasí. Artinya kajian olahraga prestasi dalam prespektif Psikologi Ölahraga cukup luas tidak hanya terbatas pada dimensi psikologis yang ada pada diri atlet yang berpengaruh terhadap prestasinya, tetapi mengkaji pula faktor-faktor of luar diri atlet seperti peran pelatih serta faktor lingkungan sosial yang berpengaruh terhadap prestasi atlet.

Secara umum Bird (1986) mengatakan bahwa kajian Psikologi Olahraga, mencakup upaya-upaya tentang perilaku individu yang terjadi dalam peristiwa olahraga, dan berbagai aspek psikologis yang dapat berpengaruh terhadap perilaku individu atau ałlet tersebut. Salmela (Gifford, 1991) mengatakan bahwa topik-topik kajian Psikologi Olahraga adalah faktor-faktor psikologis yang mempengaruhi kepribadian atlet seperti: kecemasan, motivasi berprestasi, kontrol diri, imajeri, konsentrasi dan relaksasi. Durkin (Gifford, 1991) mengatakan bahwa ruang lingkup Psikologi Olahraga meliputi, evaluasi Psikologi Olahraga, kepribadian dan prestasi olahraga, kecemasan, motivasi, agresi dalam olahraga, dinamika kelompok, dan latihan aspek-aspek kejiwaan dalam olahraga.

Berdasarkan lingkup kajian sebagaimana tersebut di atas, dapat dibedakan ada dua wilayah studi Psikologi Olahraga, yaitu: a Studi tentang pengaruh gejala.gejkala psikologis terhadap penampilan atlet, misalnya: studi tentang motivasi, kecemasan, konsentrasí, relaksasi, visualisasi, imagery, dan lain-lain.

b. Studi tentang proses sosial dalam olahraga, seperti interelasi antar atlet, atlet dengan pelatih, juga situasi-situasi yang dibentuk dibentuk oleh penonton, media masa, lingkungan masyarakat sekitar yang dapat menimbulkan dampak psikologis tertentu terhadap penampilan atlet.

\section{Peran Psikologi Olahraga}

Pada bagian terdahulu telah diuraikan bagaimana kedudukan Psikologi Olahraga dalam lingkup Psikologi sebagai pusat kajian ilmu, juga telah disampaikan ruang lingkup dan berbagai keterbatasan tentang kajian Psikologi Olahraga di Perguruan Tinggi. Sebelum disampaikan upaya pengembangan Psikologi Olahraga dalam pembangunan olahraga prestasi di indonesia, perlu kiranya terlebih dahulu melihat keadaan Psikologi Olahraga di Indonesia saat ini, membandingkannya dengan kebutuhan pembangunan olahraga, sumbangan dan keterbatasan yang dimiliki.

\section{Kondisi Psikologi Olahraga di Indonesia}

Berdasarkan pengamatan terhadap pendidikan dan kajian di Perguruan Tinggi baik negeri maupun swasta yang membuka, mengelola dan mengembangkan program studi Psikologi dan kajian terthadap berbagai literatur(jurnal dan buku Psikologi Olahraga), kondisi yang ada sampai saat ini adalah:

a. Perguruan tinggi yang mengembangkan dan mengelola Psikologi sebagai pusat kajian ilmu masih memandang Psikologi Olahraga sebagai sesuatu yang tidak penting. Hanya satu Pergursan Tinggi di Indonesia yang membuka dan mengembangkan program Psikologi Olahraga, yaitu Universtas Indonesia (UI). Di sisi lain dalam konteks pendidikan Psikologi Olahraga pada umumnya masih menggunakan buku- 
buku teks atau terjemahan dari negeranegara maju, sehingga keterkaitan dengan kondisi-kondisl lokal sangat sedikit bahkan dapat dikatakan tidak ada. Hal ini berakibat pada kurang dirasakannya relevansi dari yang diajarkan dengan kebutuhan olahraga prestasi di Indonesia.

b. Penelitian-penelitian yang sangat terbatas tu pun sebagian besar bersifat pengulangan dari penelitian di negaranegara maju, walaupun sudah mulai ada usaha-usaha untuk menyesuaikan dengan kondisi atau ciri-ciri dan kebutuhan prestasi olahraga di tan ah air.

c. Partisipasi dalam penelitian-penelitian dan program-program terapan, yang bertujuan mencari pemecahan bagi masalah-masalah olahraga prestasi sangat terbatas bahkan dapat dikatakan tidak ada baik yang dilakukan oleh para peneliti dalam rangka kerjasama antar intansi pemerintah (Perguruan Tinggi/Menpora) maupun dengan Lembaga Olahraga non Struktura! (KONI, induk organisasal cabang olahraga, dil). Hal ini menunjukkan bahwa sangat kecil minat pemerintah dan para peneliti untuk kut memikirkan masalah-masalah olahraga prestasi di Indonesia.

d. Sangat terbatasnya pakar Psikologi yang berada di berbagai Perguruan Tinggi yang mencurahkan pemikiran dan perhatiannya untuk mengembangkan berbagai bidang kajian Psikologl untuk olahraga prestasi. Kondisi Íni menyebabakan perkembangan Psikologi Olahraga di Indonesia sangat lambat

e. Partisipasi dalam penelitian-penelitian yang bersifat studi komparasi tentang olahraga prestasi dilihat dari aspek Psikologi tidak pemah dilakukan. Hal inl dengan sendirinya sangat menghambat untuk dapat mengikuti perkembangan Psikologi Olahraga di negara-negara lain.

f. Sebagian penelitian masih bersifal sporadis, dan tidak ada penelitianpenelitian longitudinal yang diajukan untuk pengembangan teori psikologi untuk mendukung pengembangan olahraga prestasi.

\section{Psikologi Olahraga untuk Menjawab Kebutuhan Olahraga Prestasi \\ Kemajuan olahraga suatu bangsa} dewasa ini sudah menjadi tolok ukur kemajuan bangsa tersebut dalam bidang lainnya. Dalam kerangka ini maka tidak heran berbagai negara berusaha menunjukkan kemampuan yang optimal dalam olahraga multievent seperti Olymplade, Asian Games, dan Sea Games. Ketika Indonesia terpuruk of posisi ke lima Sea Games Manila tahun 2005, maka Presiden Susilo Bambang Yudoyono langsung menyampaikan kekecawaannya dan mengintruksikan kepada Menteri Negara Pemuda dan Olahraga dan KONI untuk segera melakukan evaluasi. Sangat wajar kekecewaan ini muncul karena hasil Sea Games tahun 2005 merupakan prestasi terburuk dalam sejarah keikutsertaan Indonesia di Sea Games.

Menghadapl kegagalan dalam olahraga prestasi kíta harus segera melakukan instrospeksi diri dan sesegera mungkin melakukan evaluasi itu. Evaluasi harus dilakukan secara menyeluruh terhadap elemen-elemen pendukung olahraga prestasi. Selama ini pemerintah dan para praktisi olahraga belum menyadari pentingnya pendekatan ilmu keolahragaan termasuk Psikologi Olahraga dalam pembinaan olahraga prestasi.

Berbagai teori dan kajian sebagaimana yang dipaparkan di atas menunjukkan betapa penting dan strategisnya Psikologi Olahraga sebagai bagian dari ilmu keolahragaan untuk olahraga prestasi., namun di sisi lain kondisi perkembangan Psikologi Olahraga itu sendiri di Indonesia kurang begitu menggembirakan. Lantas langkah apa yang dapat dilakukan untuk mencari jalan keluar atas permasalahan tersebut di atas. Setidaknya ada dua upaya bisa of lakukan diantaranya:

a. Menumbuhkan kesadaran kepada seluruh komponen yang terlibat baik 
langsung maupun tidak langsung dalam pembinaan olahraga prestasi tentang pentingnya kajian dan aplikasi Psikologi Olahraga dalam pembinaan olahraga prestasi di Indonesia. Cara yang dapat ditempuh untuk mewujudkan hal ini melalui desiminasi hasil-hasil penelitian baik yang dilakukan d dalam negeri maupun di luar negeri, juga melalui kajian-kajian ilmiah lainnya yang dapat menyakinkan masyarakat teribat dalam olahraga prestasi.

b. Meningkatkan sumber daya manusia dalam bidang ilmu keolahragaan termasuk Psikologi Olahraga. Hal Ini bisa dilakukan dengan cara mengenbangkan SDM yang berada di lembaga Pendidikan Tinggl Keolahragaan untuk mengambil program master atau doktor dalam bidang sport science (sport psychology) d negara-negara maju, juga dengan membuka dan mengembangkan program studi Psikologi Olahraga pada Perguruan Tinggi negeri maupun swasta yang mengelola dan mengembangkan ilmu Psikologi.

\section{Simpulan}

Olahraga prestasi sudah merupakan kesepakatan rakyat indonesia sebagaimana tertuang dalam Undang-Undang Sistem Keolahiragaan Naslonal. Jika prestasi dalam olahraga seperti pada Seo Games dljadikan parameter keberhasilan pembinaan olahraga prestasi, maka bangsa kita telah jauh tertinggal dari bangsa-bangsa Asla Tenggara. Kebertasilan dalam pembinaan olahraga prestasi memerlukan dukungan IImu-ilmu keolahragaan termasuk Psikologi Olahraga. Dimensi dukungan ilmu keolahragaan ini yang kurang diperhatikan dan diaplikasikan dalam pembinaan olahraga prestasi kita, padahal berbagai kajlan telah menujukkan bahwa Psikologi Olahraga memiliki peran dan kontribusi yang kuat dalam mendukung olahraga prestasi. Di sisi lain, kajan dan pengembangan Psikologi Olahraga di Indonesia masih sangat jauh dari memadai. Perlu upaya agar
Psikolgi Olahraga sebagai bagian limu keolahragaan dapat berperan nyata dalam pembinaan olahraga prestasi di Indonesia. Upaya-upaya tersebut diantaranya : (1) menumbuhkan kesadaran kepada seluruh komponen yang terlibat baik langsung maupun tidak langsung dalam pembinaan olahraga prestasi tentang pentingnya kajian dan ap/lkasi Psikologi Olahraga dalam pembinaan olahraga prestasi di Indonesia; dan (2) meningkatkan sumber daya manusia dalam bldang ilmu keolahragaan termasuk Psikologi Olahraga balk bagi SDM yang berada di Lembaga Pendidikan Tinggi Keolahragaan maupun mereka yang mengelola dan mengembangkan Psikologi di berbagai Pendidikan Tinggi di Indonesia.

\section{DAFTAR PUSTAKA}

Anshel, M.H. 1990. Psycholagy Sport From Theory to Practice. Scottsdale Arizona: Gorsuch Scarisbbrick Publishers.

Bird, A.M., \& Cripe, B.K. 1986. Psychology and Sport Behavior. St. Louls: Times Mirror/Mosby College Publishing.

Bompa, T.O. 2000. Total Training for Young Champions. USA: Human Kinetics.

Carlson, N.R. 1986. Psychology The Science of Behavior. Parls: A.D.A.G.P. Inc.

Cox, R 2002. Sport Psychology Conceps and Applications. New York: Mc Graw-Hiii.

Davies, D. 1989. Psychological Factors in Competitive Sport, Philadnelphla: The Falmer Press Taylor \& Francis Inc.

Freeman,W.H. 1987. Physical Education and Sport in A Changing Society. New York. Mayfleld Publishing Company. 
Gifford, R 1991. Applied Psychology Variety and Opportunily Massachusets: Simon \& Schuster, Inc.

Haag, H. 1994. Theorelical Foundalion of Sport Science as a Scjentific Disipline Contribution to a Philisophy (Mela-Theory) of Sport Science. Fedral Republtc of Germany: Verlag Karl Hofimann Schondorf.

Lutan, R. 1997. Manusia dan Olahraga. Bandung: ITB

Nossek, J. 1982. General Theory of Trainning. Lagos National Instltute for Sport: Pan African Press Ltd.

Pate, R.R., McCleanaghan, B., \& Rotella, R 1993. Scientific Foundations of Coaching (terjemahan Kasiyo Dwijowinoto), Semarang: IKIP Semarang Press.

Setyobroto, S. 1989. Psikologi Olahraga. Jakarta: PT Anem KosongAnem.

Setyobroto, S. 1993. Psikologi Kepeiatihan, Jakara: CV Jaya Sakti.
Singgih, D.G. 2004. Psikologi Olahraga Preslasi. Jakarta: PT BPK Gunung Mulya.

Singgih, D.G. 1989, Psikoiogi Olahraga. Jakarta: PT BPK Gunung Mulya.

Singgih, G, Setiadarma, M.P., \& Myrna, H.R.S. 1996. Psikologl Olahrga: Teori dan Praktis, Jakarta: PT BPK Gunung Mulya

Straub, F. W. 1980. Sport Psychology An Anaiysis of Athele Bohavior. New York: Movement Publication.

Undang-undang Republik Indonesia Nomor: 3 Tahun 2005 Tentang Sistem Keolahragaan Nasional (2005). Jakarta: Kementrian Negara Pemuda dan Olahraga Republik Indonesia.

Wasti, S 1988. PenganlarPsikologi. Jakarta: BinaAksara.

Weinberg, R.S \& Gould, D. 2003. Foundation of Sport and Exercise Psychoiogy. Champaiggn, L. Human Kinetics. 